\title{
Potential hazard consequences to personnel exposed to the ignition of small volumes of weakly confined stoichiometric hydrogen/air mixture
}

\author{
J.M. Ingram $^{1}$, A.F. Averill ${ }^{1 *}$, L. Gomez-Agustina ${ }^{2}$, P.G. Holborn ${ }^{1}$, P. Battersby ${ }^{1}$ and C. \\ M. Benson ${ }^{1}$. \\ London South Bank University (LSBU), London SE1 0AA UK. \\ ${ }^{1}$ Hydrogen Hazards Unit. ${ }^{2}$ Acoustics Research Group - School of Built Environment and \\ Architecture.
}

\begin{abstract}
Many studies have been devoted to understanding the consequence of ignition events that could occur as a result of using hydrogen as an alternative to fossil fuels or when hydrogen is present in large scale industrial or nuclear waste sites. Little attention has however, been given to the effect of explosion in small scale operations: this could involve service work with manual handling and manipulation of gas containing packages or vessels. The purpose of this study is to begin to address this knowledge gap and report the results of an experimental program carried out to simulate the effect of localised and weakly confined small volume hydrogen explosions on personal safety. Three aspects of personal injury consequences are considered; injury from shock loading to the head/brain, skin burns and acoustic/hearing damage. It is concluded from ignition and acoustic noise exposure experiments, carried with stoichiometric hydrogen /air mixtures, that injuries arising from shock loading or burns to the skin are less likely than hearing damage. It is suggested that further work should focus on the noise exposure and hearing damage effects of small scale explosions.
\end{abstract}

Keywords: ignition; small-scale; personnel hazard; hearing damage; skin burns; head injury

\section{Introduction}

Much has been written in recent years about the future of hydrogen as an alternative to fossil fuels [1-10] and the challenges that ensue concerning safety aspects involving hydrogen containment or storage. These safety aspects are also of great importance in the context of nuclear decommissioning operations where hydrogen issues arise due to the corrosion of nuclear waste [11-14].

The much lower density of hydrogen than air gives it a large degree of buoyancy so that in this respect it can be considered to be inherently safer than other flammable gases in unconstrained and well ventilated spaces. On the other hand, the wide flammability range of the gas in air makes the likelihood of ignition greater. Zhang and $\mathrm{Li}$ [1] compared the explosion characteristics of large volume hydrogen, propane and methane clouds at the stoichiometric concentration. As would be expected, the hydrogen/air cloud explosion was found to have the highest peak overpressure with the overpressure rising at the

* Corresponding author. E-mail address averilla@1sbu.ac.uk 
nearby locality of the cloud boundary. The dynamic pressure of the cloud explosion was found to be of similar order to the overpressure and the explosion/flame region approximately 1.25 times the original width of the cloud. Dadashzadeh et al. [2] have recently provided a risk assessment methodology for onboard hydrogen-powered vehicle storage. The fire risk is defined in terms of "cost of human life per vehicle fire, and annual fatality rate per vehicle". Hazard distances were calculated for blast wave and fireball following a catastrophic storage tank rupture. They found that the resulting fire acts in all directions with larger hazard distances in comparison with a jet fire.

An evaluation of the common hazards associated with hydrogen storage facilities and distribution systems was carried out by Rigas and Sklavounos [3]. They reported that their hazard analysis had shown that hydrogen ignition can result in accidents that "pose a severe threat for property and public safety". Interestingly, they also found that the resulting cloud arising from liquefied hydrogen spillage behaves as a heavy gas rather than a light one with flammable concentrations remaining at low heights above the ground. Particular safety concerns have been highlighted where $\mathrm{H}_{2}$ fuel cells have replaced lead-acid batteries for industrial forklift operation [4]. Safely refuelling these trucks with compressed hydrogen in a confined space offers new challenges and requires further operational considerations. In their experiments, Ekoto et al. [4], used a sub-scale test facility ( $45 \mathrm{~m}^{3}$ internal volume) with Froude scale-up calculations to simulate the release of $0.8 \mathrm{~kg} \mathrm{H}_{2}$ into a $1000 \mathrm{~m}^{3}$ enclosure. Dispersion measurements showed that the transient release plume first became a momentum guided jet (relatively insensitive to buoyancy) which quickly diverted upwards as the storage tank pressure decreased. Tanaka et al. [5] have carried out an experimental study on hydrogen explosions in a fullscale hydrogen filling station. High pressure hydrogen was released into the storage room in the full-scale model of the refuelling station. Igniting the releases showed that the overpressures generated had a clear correlation with the timing of ignition and distance from the ignition point.

Many studies have been devoted to understanding the likelihood and consequence of ignition events that could occur in large scale industrial or nuclear waste sites. For example, in a recent paper, Averill et al. [14] examined how Bayesian networks could be used to represent and understand potential ignition scenarios in nuclear waste decommissioning. In the work, prediction of the hydrogen concentration produced by corroding pyrophoric material contained in large stacked storage boxes was explored and related to a number of operational parameters. However, in contrast to the large-scale or relatively large-scale ignition and safety studies carried out, little attention has been given to the effect of ignition in small scale operations such as service work involving manual manipulation of gas containing packages or vessels. A great deal of personal operational intervention may be required in practical processing rather than the use of remote, engineered systems. In one nuclear processing scenario for example, a rebottling activity for analytical purposes requires that operators in air fed suits pick up and move packages/bottles that contain hydrogen. There is an increasing interest in the personal injury consequences of ignition of small volumes of gas containing hydrogen during such operations. These may result from localised hydrogen leaks released to air with an external ignition source or through an internal ignition source that results in deflagration 
of the contained flammable gas mixture. Concerning this 'hands on' processing activity, conventional/personal safety management must be considered to be of the greatest importance. Although there have been reports and discussions on the effects of explosions on the body (e.g. in the Oklahoma City bombing [15]) the consequence of exposure to ignition of small volumes of localized flammable hydrogen leaks is difficult to estimate theoretically and there appears to be little industrial evidence or literature to refer to.

The purpose of this paper is to address this knowledge gap and to report the results of an experimental program carried out to simulate the effect of localised (weakly confined) small volume hydrogen explosions on personal safety. Of particular importance is identifying the most serious consequences that require further study.

\section{Potential hazards}

With any explosion event there are several ways in which injury could be caused to people in its proximity. These can be categorised as being due to the effects of the blast/shock wave or the resulting flying fragments/projectiles, burns or hearing damage. Many of the issues involved have been examined in other studies but these have typically been on much larger scales or involved small high explosive charges producing shock waves much greater than produced by weakly confined hydrogen gas explosions. One approach in determining the effect of an explosion is to make a comparison with published data on the basis of TNT equivalence but the fraction of the TNT equivalence value actually realised in an unconfined or mostly unconfined explosion is only a few $\%$ of the destructive effect indicated by the equivalence value. It would be very unclear as to what fraction should be assumed in the case of a small gas filled bag of a few litres. A better indication of explosive energy in this case is to take account of the equivalence ratio $(\Omega)$ of the hydrogen gas mixture since an equivalence ratio of 1 corresponds to peak overpressure in an enclosed volume. Although $\Omega=1$ does not correspond to the concentration at which the maximum burning velocity occurs it can be considered to be (or close to being) a worse case scenario regarding blast pressure and acoustic noise.

One area of the body that is particularly prone to suffer serious injury from shock loading is the head/brain. The shock loading could result either from the blast itself or from a projectile impacting the head. This has been investigated in a number of different contexts such as traffic collisions, sporting injuries and blast suits for improvised explosive devices (IEDs) [16]. The likelihood of serious injury is related to both the magnitude and duration of the g-force experienced. Based on this, one of the earliest and most widely used measures for head injury is the Wayne State Tolerance Curve [17], shown in Figure 1. This in turn has led to the development of criteria such as the Head Injury Criterion (HIC). A full discussion of the sensitivity of the various biomechanical measures of head impact (rotational and linear acceleration, impact duration and location) to the clinical diagnosis of concussion has been given by Greenwald et al. [18]. 


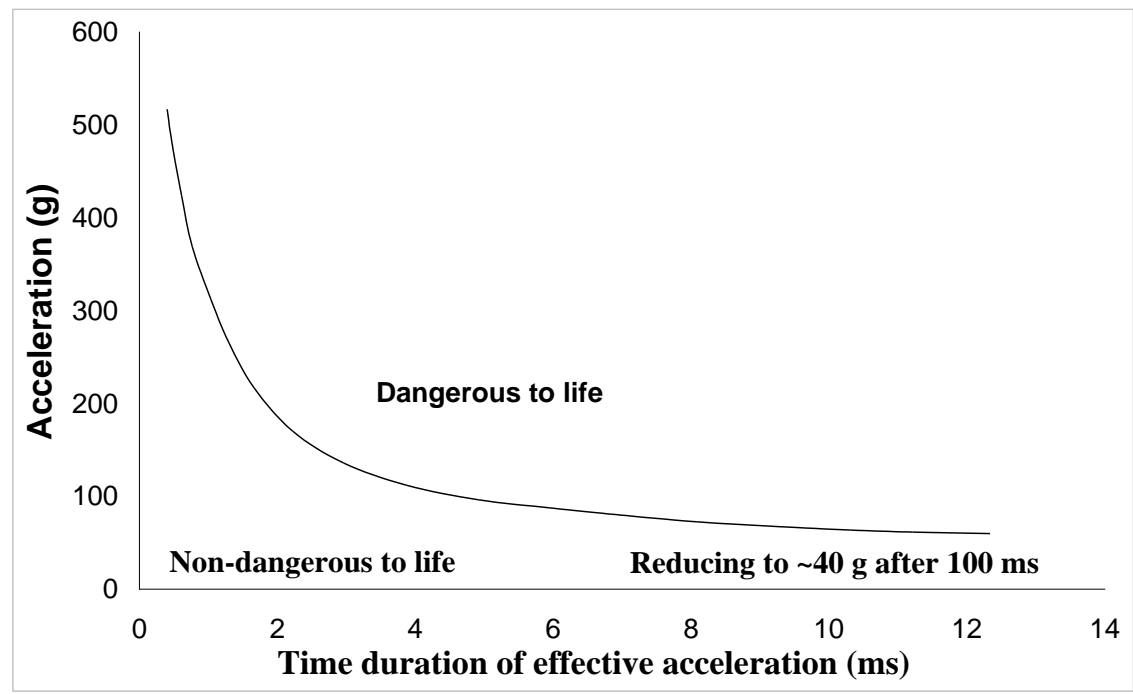

Figure 1 The Wayne State Tolerance Curve defines an injury threshold based on the onset of skull fracture.

Another area of major concern is that of burns. The conditions necessary to cause burns (i.e. temperature and time) are well known. Damage to the skin with 1st degree burns begins once the temperature of the basal layer (deepest layer of the five layers of the epidermis) reaches $44^{\circ} \mathrm{C}$. Should the basal layer reach $72^{\circ} \mathrm{C}$ then the skin will be destroyed instantly [19]. However, in the case of nuclear or industrial process workers likely to be exposed to effects from ignition of small volumes of hydrogen, it is highly unlikely that direct impingement of flames onto bare skin would occur. Workers should invariably be wearing protective equipment, typically air-fed suits of polymeric material covering the entire body for radiological protection. In a small localised hydrogen explosion, High flame temperatures will be generated $\left(2000^{\circ} \mathrm{C}\right)$ but only for a very short period of time (typically $\left.<0.1 \mathrm{~s}\right)$. This raises the important question of whether the heat flux and its duration would be sufficient to ignite/damage the film and burn the skin directly or instead permit enough heat transfer through the intact film to damage skin underneath.

Hearing damage is a significant concern following any explosion and often occurs in situations where persons are otherwise uninjured. The human hearing system is an extremely delicate and sensitive detector of pressure fluctuations in the air. Despite its large range of detection, high levels of impulsive sound arising from explosions or industrial processes can carry excessive acoustics energy posing a considerable risk to the hearing system of the person exposed. Instant damage can occur to the middle and/or and inner ear from high level impulsive sounds resulting in permanent hearing loss.

In the European Union, the Directive 2003/10/EC (noise) ${ }^{\dagger}$ stipulates the minimum health and safety requirements regarding the exposure of workers to the risks arising or likely to arise from noise and in particular the risk to hearing. The Directive defines the physical parameters that serve as risk predictors in noise exposure assessments. The $\mathrm{C}$-weighted peak sound pressure level ( $\mathrm{LC}_{\mathrm{peak}}$ ) is specified as the parameter to be used for measuring

${ }^{\dagger}$ This is implemented in the UK as the Control of Noise at Work Regulations 2005 [21]. 
and assessing noise exposure from impulsive sound sources. It also designates legal obligations for employers when certain exposure limit levels of those parameters are reached or exceeded. Under the Directive, employers are required to implement a programme of technical and organizational measures to reduce the level of exposure if an employee is likely to be exposed to sounds measuring $\mathrm{LC}_{\text {peak }}$ of $137 \mathrm{~dB}$ or above. An absolute limit is placed at $140 \mathrm{~dB}$ which must not be exceeded. Only for this limit can the reduction afforded by hearing protection be taken into account in the exposure assessment.

Impulsive noise sources investigated previously have included fireworks as well as various kinds of weapons and explosive devices. Of particular relevance is the study of acoustical characterisation of exploding hydrogen-oxygen balloon carried out by Vernon and Gee [20]. In this study, balloons of 231 capacity were filled with varying amounts of hydrogen and oxygen and then ignited in an anechoic chamber using a small butane torch attached to a metre stick. Although the issue of hearing damage was not directly addressed, acoustic data was collected over a spherical surface geometry at a radial distance of mostly $1.83 \mathrm{~m}$. At this distance, the lowest $\mathrm{L}_{\text {peak }}$ value measured was 126.1 $\mathrm{dB}$ with a balloon containing 1.981 of hydrogen in the absence of oxygen. The highest $\mathrm{L}_{\text {peak }}$ value $(161.5 \mathrm{~dB})$ found was for a balloon filled with 22.11 of stoichiometric mixture of hydrogen/oxygen. It was also observed that balloons filled with pure hydrogen showed more variability in the results obtained whereas the balloons that also contained oxygen produced more consistent sound levels that grew with the balloon size.

It is expected that because of the need for process workers to closely inspect and visually examine packages for degradation, the head would be at most risk and potentially subjected to the full force of any explosion blast. For this reason, to carry out an experimental program which would throw most light on the personal damage and injury likely to be caused by a small localized hydrogen gas explosion, it was decided that measurements should be made using an exploding gas sac or balloon in the proximity of a simulated human head. The following parameters were considered most important for measurement; force and movement experienced by the simulated head mass, blast pressure and noise exposure levels, and surface temperatures in the facial region. To represent a worse case scenario, all tests were carried out with a stoichiometric hydrogen /air mixture $(\Omega=1)$.

\section{Experimental Apparatus}

The experimental apparatus was assembled as shown in Figure 2.

\footnotetext{
$\$$ It was noted by the authors that the $\mathrm{L}_{\text {peak }}$ values were similar to the $\mathrm{C}$ weighted results which were not specifically given.
} 


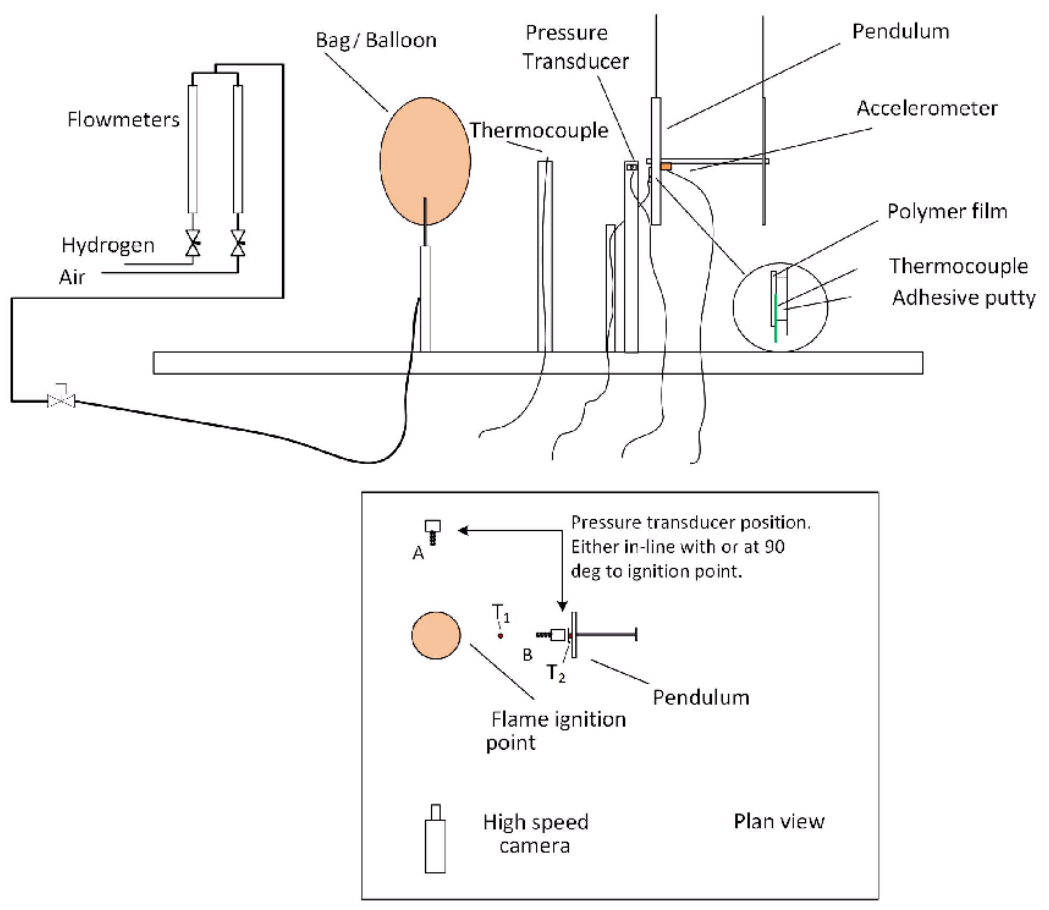

Figure 2. Schematic diagram of exploding sac/balloon test apparatus

A $30 \%(\mathrm{v} / \mathrm{v})$ stoichiometric hydrogen/ air gas mixture was supplied to the sac/balloons from a blending panel through a solenoid valve that could be operated remotely. Polyethylene zip-tie plastic sacs or heavy duty seam welded PVC sacs (supplied by Sellafield Ltd) were sealed in the deflated condition and filled through an inserted hypodermic needle. The latex composition balloons used in the tests were directly filled through a nozzle with the gas mixture to the required volume and sealed. To initiate an explosion, a small propane blow torch was used attached to a $2 \mathrm{~m}$ long rod, the flame allowed to contact the sac/balloon surface in a position outside of the line of the measuring devices. Attempts to use an electric arc from a $10 \mathrm{kV}$ ignition transformer for this purpose proved unsuitable on account of the electrical noise produced interfering with the triggering and measurement systems. The ignition events were recorded with high speed digital imaging using an Olympus i-speed camera at $1000 \mathrm{fps}$.

\section{Pendulum and accelerometer for simulated head movement}

A ballistic pendulum was constructed to proximately simulate a workers head. It consisted of a circular plate (230 mm diameter) attached by a threaded rod in its center to a steel bar (200 $\mathrm{mm}$ x $40 \mathrm{~mm} \times 5 \mathrm{~mm}$ thick). The pendulum was suspended, from a height of $1.25 \mathrm{~m}$ to the centre of the plate, by 3 steel cables; two attached to the plate and the third to the bar at the rear. Initial tests were conducted using a $6 \mathrm{~mm}$ thick steel circular plate $(1.9 \mathrm{~kg}$ ) with a centrally attached $100 \mathrm{~mm}$ diameter steel disk of mass 2.5 $\mathrm{kg}$. Together with the rod and bar this gave a total mass of $5 \mathrm{~kg}$ which is comparable to the mass of a human head. In later tests this was reduced by using a $5 \mathrm{~mm}$ thick Perspex 
disk to give a total mass of $0.8 \mathrm{~kg}$. A marker was applied to the edge of each disk to enable its movement to be tracked during analysis of the high speed digital imaging.

Attached to the threaded rod, immediately behind the back of the disk was a single axis \pm $250 \mathrm{~g}$ accelerometer (EVAL-ADXL001-250Z) operating at $5 \mathrm{~V}$ to give a specified output of $6.7 \mathrm{mV} / \mathrm{g}$. A $75 \mathrm{kHz}$ low pass filter was attached to the output and a differential op-amp circuit used to remove the zero bias voltage.

\section{Pressure transducer for blast measurement}

To record blast pressure levels, a Honeywell piezoresistive 26PCAFA6D 0 to 1 psi, (0 to $6895 \mathrm{~Pa}$ ) differential pressure transducer was used that enabled a maximum measurement response time of $1 \mathrm{~ms}$. One of the outlets of the differential transducer was exited through a rigid pipe to the atmosphere at a distance of $5 \mathrm{~m}$ from the blast so that it was referenced to normal atmospheric pressure. The position of the transducer and its orientation was varied as shown in Figure 2, placed in one of two positions to give either a general in line record of the blast pressure $(\mathrm{A})$ or a direct indication of the pressure close to the pendulum (B. i.e. the human head position). Output from the transducer was amplified using a Burr Brown INA125 instrumentation amplifier and precision voltage reference IC circuit. The amplified sensor output was calibrated against a mercury manometer.

\section{Temperature measurement and film surface ignition}

Temperature measurements were made using two fine bare wire $(0.13 \mathrm{~mm}$ dia.) $\mathrm{k}$ type thermocouples to provide rapid response and minimise thermal lag. The thermocouple outputs were amplified using an AD595 thermocouple amplifier to give a linearised output of $10 \mathrm{mV} /{ }^{\circ} \mathrm{C}$. One of the thermocouples ( $\left.\mathrm{T}_{1}\right)$ was placed between the sac/balloon and the pendulum for the purpose of triggering the oscilloscope after an explosion. The second $\left(\mathrm{T}_{2}\right)$ was placed under a layer of polymer film $(0.37 \mathrm{~mm}$ thick glove material $)$. The glove material test pieces $(20 \times 40 \mathrm{~mm})$ were attached to the front of the pendulum with a thin layer of adhesive putty to represent the presence of facial skin or its protective cover. A small section of the film was allowed to overhang the edge of the putty to maximise the chance of realizing ignition or physical damage.

\section{Acoustic measurements for noise exposure assessment}

Acoustic measurements were made to determine peak sound pressure levels at the proximate head position. These were carried out using a fully calibrated sound level meter (SLM): Norsonics-140 conforming to BS EN 60804: 2001 [22] Class I of SLM. To avoid the possibility of instrument damage, measurements of $\mathrm{LC}_{\text {peak }}$ were taken at a distance $4.2 \mathrm{~m}$ (in an unimpeded line of sight) from the point of an exploding sac/balloon (Figure 3). $\mathrm{LC}_{\text {peak }}$ levels at the assumed distance of $0.6 \mathrm{~m}$ (i.e. approximate arms length) between the unprotected ear of the employee and the center of the exploding bag were predicted using room acoustics theory taking into account reverberation time data for the 
laboratory. The necessary reverberation time measurements and calculations were made in accordance with BS ISO 3382-2: 2008 [23] using the SLM.

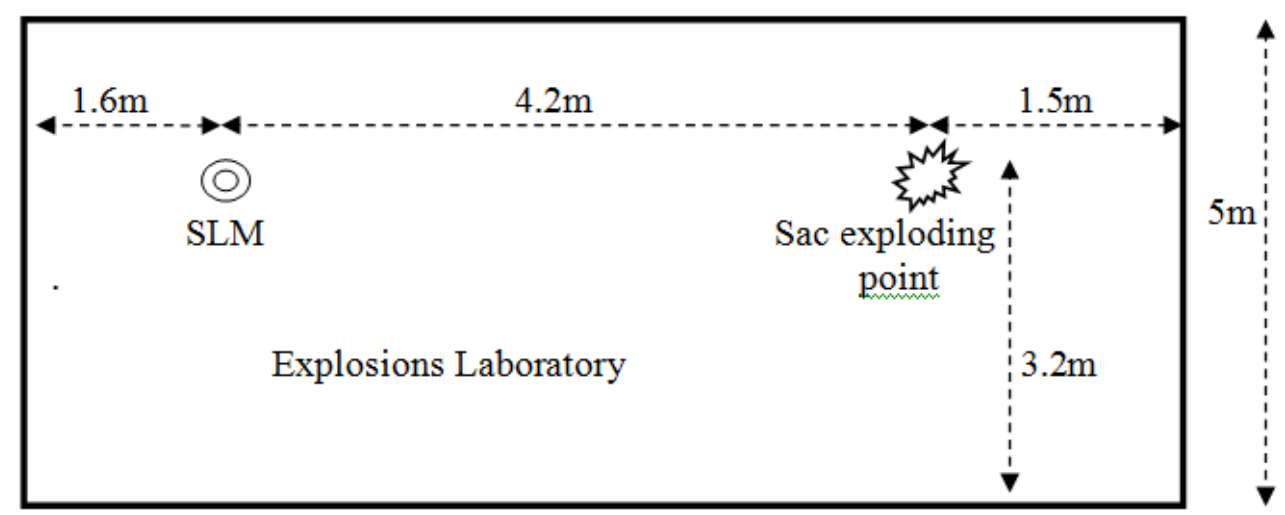

Figure 3. Plan view of the peak sound pressure level measurement arrangement showing the laboratory dimensions and distances between the SLM and exploding sac/balloon position. The SLM is positioned at a height of $1.5 \mathrm{~m}$ from the floor. Laboratory height $6 \mathrm{~m}$.

\section{Data logging the measurements}

The outputs from the pressure sensor, thermocouples and accelerometer were recorded using a 4 channel $100 \mathrm{MHz}$ mixed signal storage oscilloscope (Agilent Technologies Model MSO-X 3014A) to enable capture of data. It was found that the most reliable option for triggering the oscilloscope reading was to activate it on the leading edge response of the thermocouple $\mathrm{T}_{1}$.

\section{Experimental methodology}

Tests were conducted in a straightforward sequence. Firstly the solenoid valve was opened and the hydrogen and air flow meters adjusted to give the required concentration. After closing the valve and positioning a sac or balloon in place, the solenoid valve was opened again and the sac/balloon filled. The oscilloscope was then set to wait for trigger until the high speed camera was triggered manually prompted by ignition of the gas mixture. Finally, measurement data was collected and the high speed digital images examined using Olympus "De-luxe" i-speed tracking software to calibrate and analyse the movement of the pendulum plate. This also enabled an estimate to be made of the duration of the explosion event, of great importance as discussed earlier in the context of HIC. The logged data was analysed to obtain peak pressure values, accelerations and temperatures. 


\section{Results}

Since sacs made of relatively un-elastic material are more likely to be representative of the flexible gas containing vessels used in the nuclear/process industries, zip-tie polyethylene sacs were used for the majority of the experiments filled to a capacity of 3.3 litres. Rubber balloons were also used to give some information and understanding of how elastic containers, which forcibly contract from the gas mixture on puncturing, influence the explosion hazard. These were filled to a capacity of approximately 4 litres which, allowing for the elastic properties of the balloon material would have resulted in an internal pressure $2-4 \%$ above atmospheric. The plastic protection suit material used by process operatives was simulated using polymer glove material $(0.037 \mathrm{~mm}$ thick $)$ directly covering and in contact with thermocouple $\mathrm{T}_{2}$.

\section{Tests with the $5 \mathrm{~kg}$ pendulum}

Tests were first carried out using the $5 \mathrm{~kg}$ pendulum to simulate the mass and cross sectional area of a human head with the pressure sensor located in position A (Fig. 2) to register the overpressure produced by ignition of gas mixture in a sac. From the high speed digital imaging it was apparent that the deflagration event lasted for some $20 \mathrm{~ms}$ and that the flames and combustion products clearly impinged on the pendulum and the polymer film. No movement was detected of the pendulum resulting from the blast as can be seen from the selected image frames of the ignition progress given in Figure 4. This was confirmed by the lack of any acceleration force registered by the accelerometer. The pressure time history of the ignition in Fig.5 shows an initial positive peak of $0.4 \mathrm{kPa}$ which rapidly goes negative indicating a suction phase before rapidly returning to atmospheric pressure. It should be noted that the zero time on the plot is referenced to the temperature response and as such does not directly correlate with the times of the images given in Fig.4. The temperature response $\left(\mathrm{T}_{2}\right)$ as recorded on the underside of the polymer glove material (Fig. 6), shows that even though the digital images reveal combustion flames impinging on the material, the temperature rise is only approximately $3^{\circ} \mathrm{C}$. Furthermore, inspection of the film after the test did not indicate any sign of damage. 

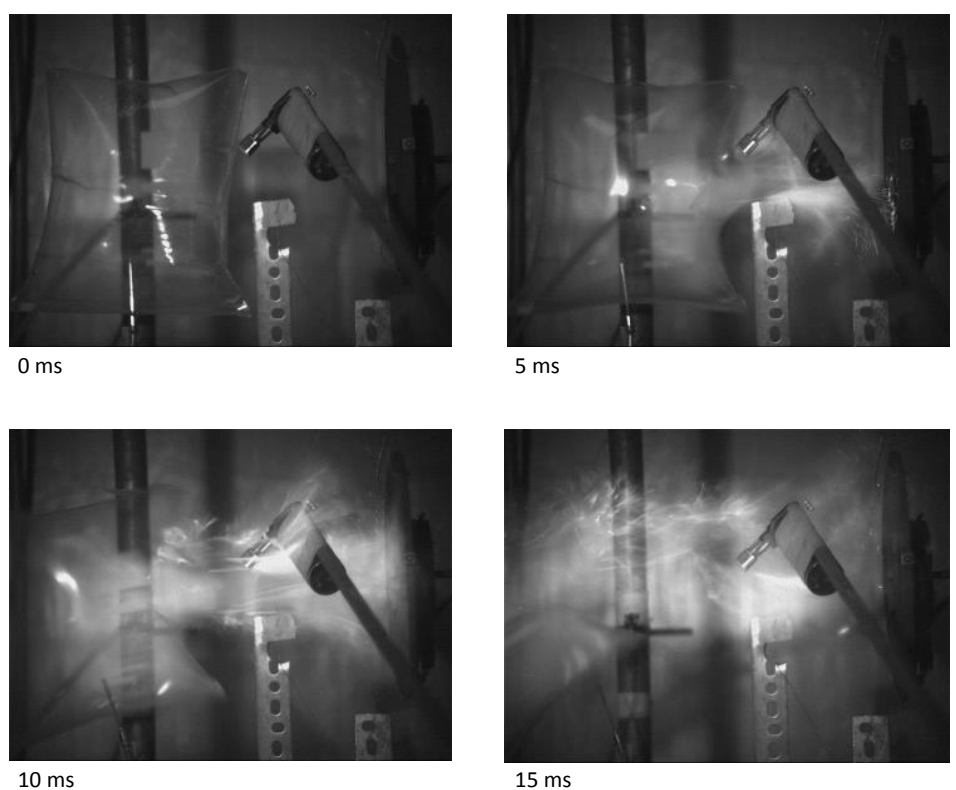

Figure 4. Image frames from ignition of stoichiometric $\mathrm{H}_{2} /$ air mixture in zip-tie sac with the $5 \mathrm{~kg}$ pendulum.

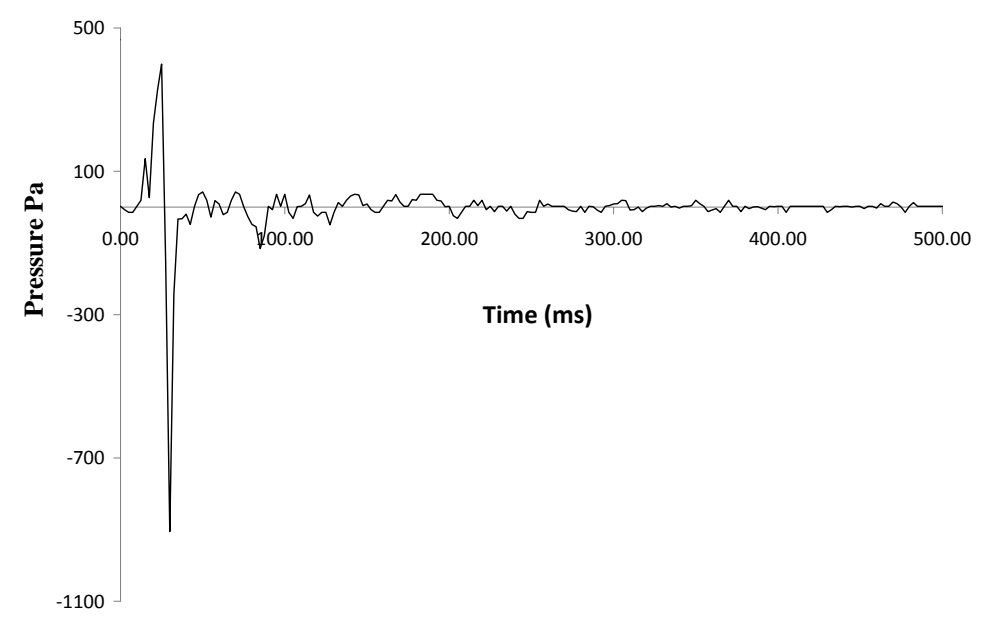

Figure 5. Pressure-time history for ignition of stoichiometric $\mathrm{H}_{2} /$ air mixture in zip-tie sac with the $5 \mathrm{~kg}$ pendulum and pressure sensor in position $\mathrm{A}$. 


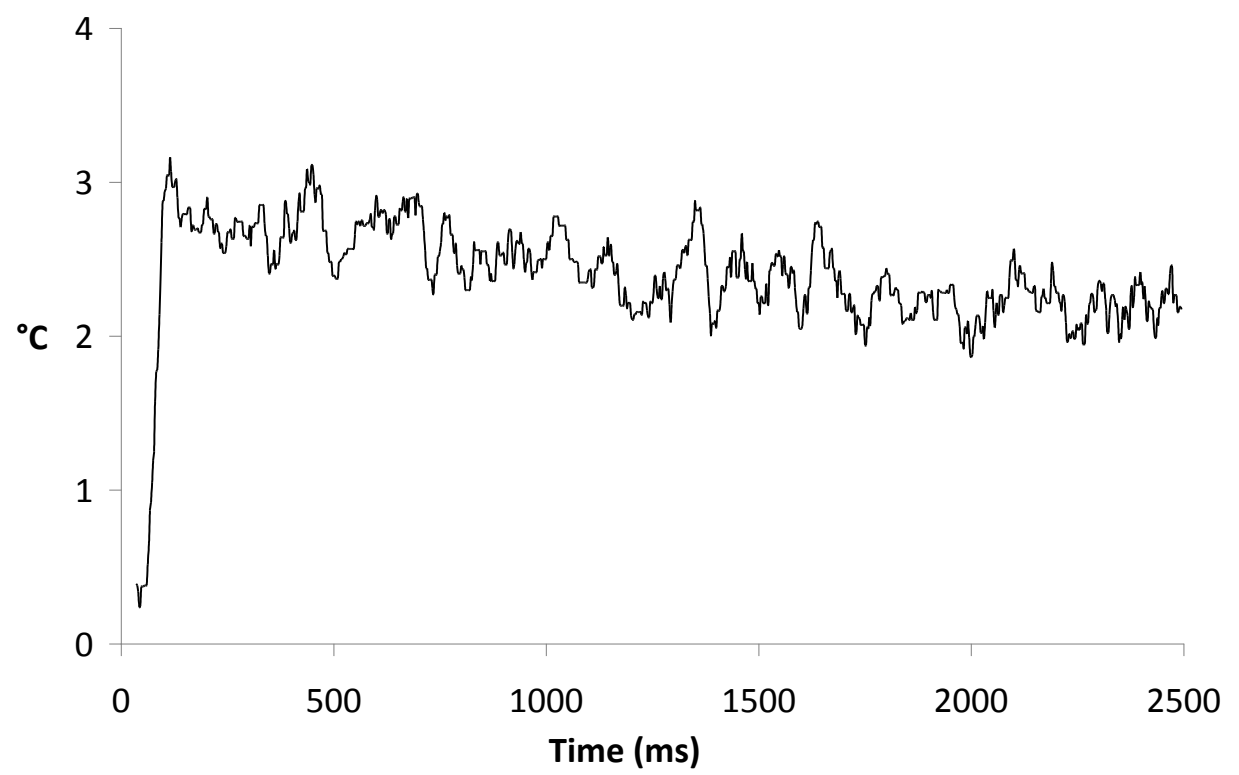

Figure 6. Temperature $\left(\mathrm{T}_{2}\right)$ rise-time history for ignition of stoichiometric $\mathrm{H}_{2}$ /air mixture in zip-tie sac with $5 \mathrm{~kg}$ pendulum.

Tests were then carried out under similar conditions substituting balloons for the zip-tie sacs. It can immediately be seen from Figure 7, which shows image frames from the high speed video, that there are significant differences in the explosions with balloons and ziptie sacs. With the zip-tie sacs, the flames and combustion products are very clearly directed away from the point of ignition whereas with balloons the skin of the balloon retracts very rapidly leaving a ball of pre-mixed flammable atmosphere which ignites to produce a flame extending more evenly in all directions. The peak temperature recorded by the thermocouple between the balloon and pendulum was approximately $550{ }^{\circ} \mathrm{C}$. For a beaded thermocouple with even such fine wire as used here $(0.13 \mathrm{~mm})$ thermal lag is still significant with a time constant of around $0.135 \mathrm{~s}$ [24]. Since the period of temperature rise during the explosion was around $100 \mathrm{~ms}$ and that of the visible flaming $90 \mathrm{~ms}$, the time constant implies that substantially less than $50 \%$ of the instantaneous temperature rise would have been recorded. Taking into account this difference it is unsurprising that the recorded temperature is much smaller than the adiabatic flame temperature for a stoichiometric hydrogen/air mixture (2483K). Figures 8 and 9 show the data recorded from the pressure sensor (position A) and thermocouple behind the polymer film. The pressure time history is similar to that observed for the zip-tie sacs but the initial positive impulse is greater $(1.13 \mathrm{kPa})$ consistent with the effect of a less directional blast on the transducer in position A. As with previous zip-tie sac tests, only a small temperature rise $\left(1.5^{\circ} \mathrm{C}\right)$ was detected behind the polymer film and the accelerometer did not record any acceleration of the pendulum. It can be seen from Fig. 9 that there was an initial rapid temperature rise of $0.5^{\circ} \mathrm{C}$ over a period of $100 \mathrm{~ms}$ coinciding with the duration of the temperature rise recorded by the other thermocouple. Unlike the zip-tie sac tests, the temperature of the film then continued to increase slightly. 

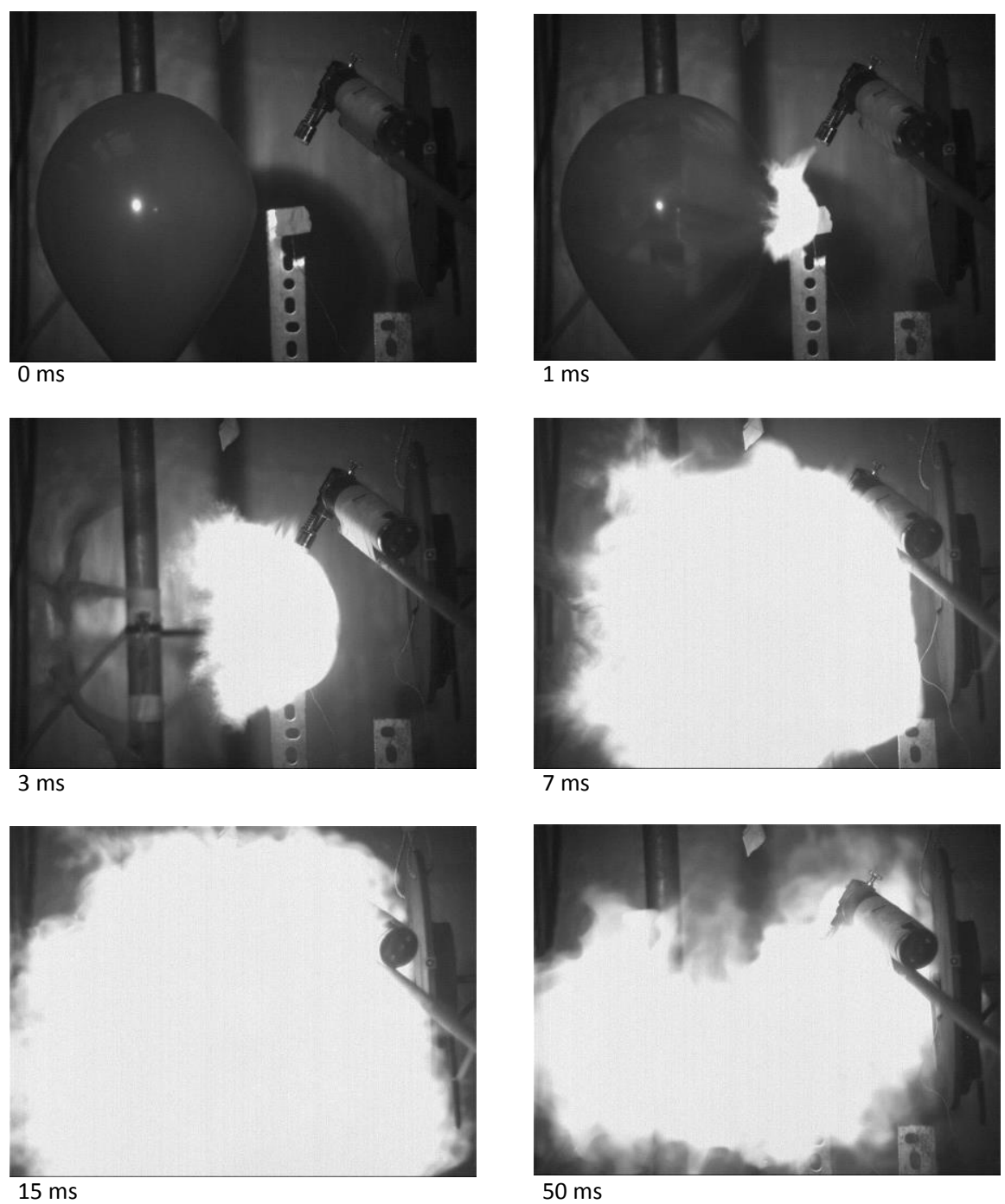

$50 \mathrm{~ms}$

Figure 7. Image frames from the ignition of stoichiometric $\mathrm{H}_{2} /$ air mixture in a balloon with the $5 \mathrm{~kg}$ pendulum. 


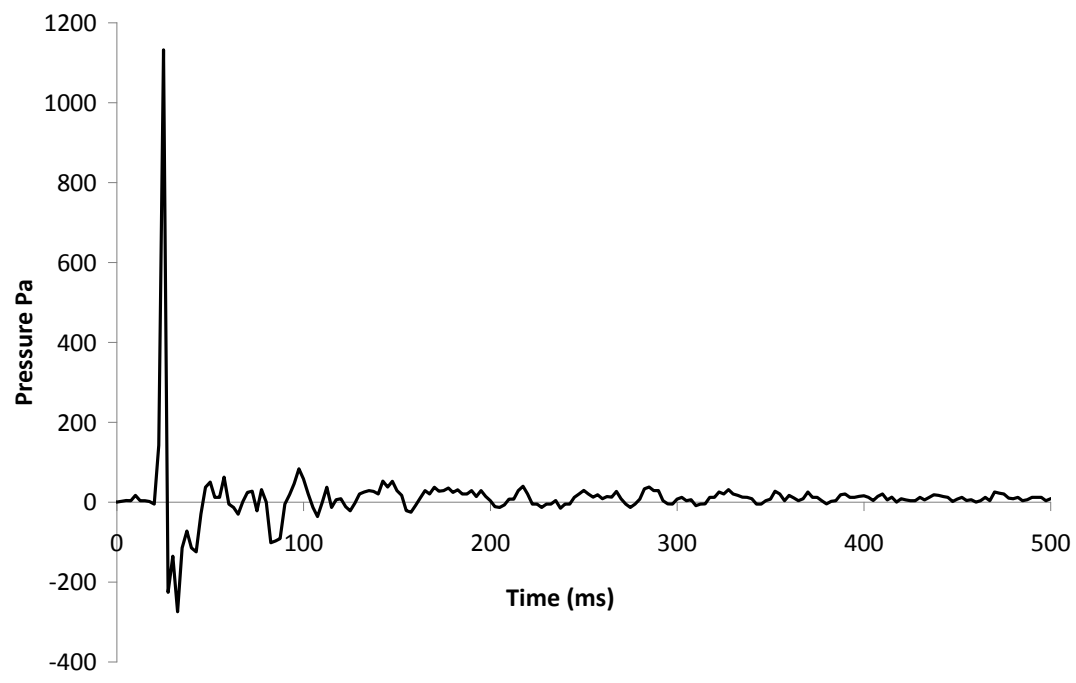

Figure 8. Pressure-time history for ignition of stoichiometric $\mathrm{H}_{2}$ /air mixture in a balloon with the $5 \mathrm{~kg}$ pendulum. Pressure sensor in position A.

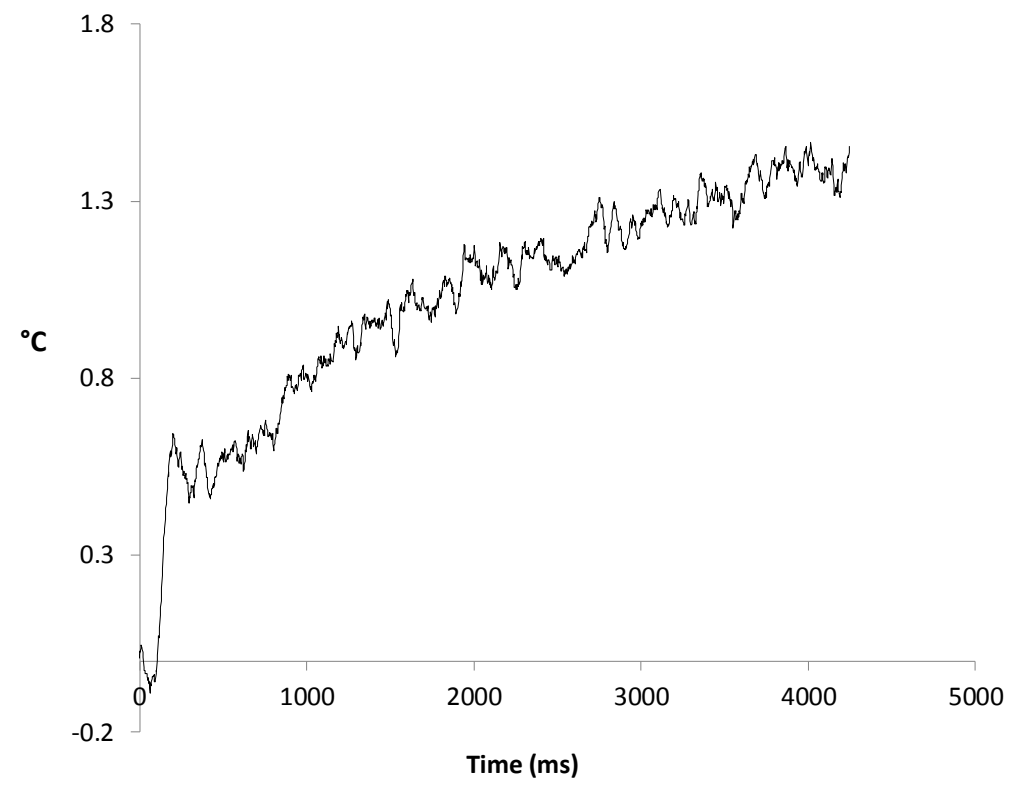

Figure 9. Temperature $\left(\mathrm{T}_{2}\right)$ rise time history for ignition of stoichiometric $\mathrm{H}_{2}$ /air mixture in a balloon with $5 \mathrm{~kg}$ pendulum. 


\section{Tests with the $0.8 \mathrm{~kg}$ pendulum}

Since no movement of the $5 \mathrm{~kg}$ pendulum was detected in the experiments, a further series of tests with gas filled zip-tie sacs were carried out with the much lighter Perspex disc $(0.8 \mathrm{~kg})$ and locating a pressure sensor in position B to determine the blast pressure close to the pendulum (simulated head position). The image frames for ignition of a gas filled zip-tie sac and the $0.8 \mathrm{~kg}$ pendulum (Fig. 10) show that the general progression of the explosion appears similar to that which occurs with the $5 \mathrm{~kg}$ pendulum. Although it cannot easily be seen from the still images, analysis of the high speed video indicated significant movement of the $0.8 \mathrm{~kg}$ pendulum with some superimposed vibration.

Tracking of the markers on the pendulum indicated that the blast rapidly accelerated the pendulum to a stable net directional velocity of $0.16 \mathrm{~m} / \mathrm{s}$ over a period of a few milliseconds. Consistent with data recorded from the accelerometer, this suggests that the blast force could result in an initial net directional acceleration of about $5 g$. The accelerometer measurements also showed that the initial net unidirectional acceleration was followed by a (net zero) fluctuating acceleration of up to around $\pm 6 \mathrm{~g}$.
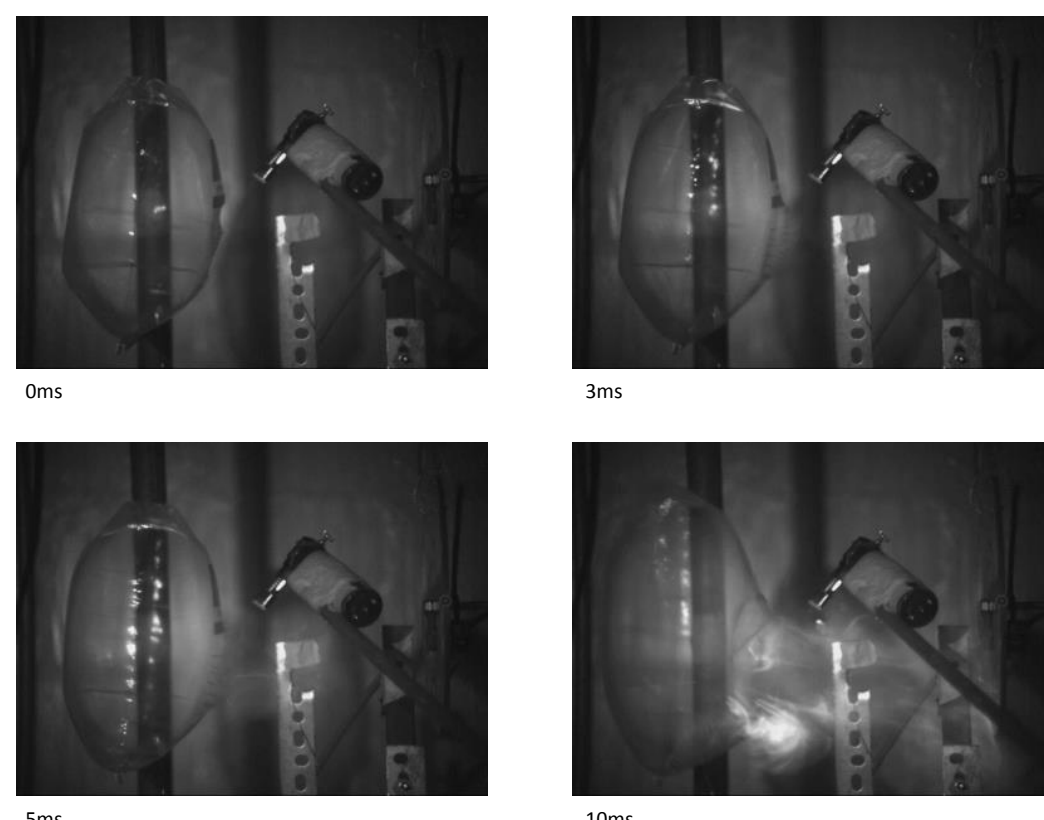

$10 \mathrm{~ms}$
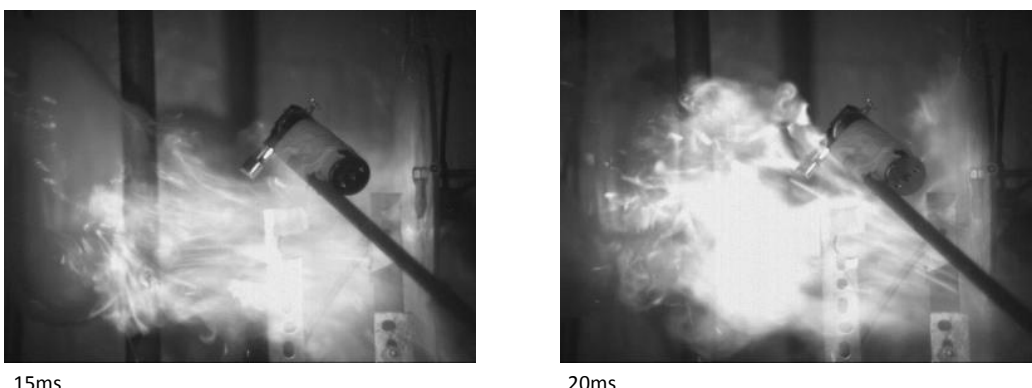

$20 \mathrm{~ms}$

Figure 10. Image frames from ignition of stoichiometric $\mathrm{H}_{2} /$ air mixture in a zip-tie sac with the $0.8 \mathrm{~kg}$ pendulum. 
The pressure time history recorded for the sensor in position B indicated that the initial acceleration of the pendulum coincided with an impulsive pressure peak of approximately $1 \mathrm{kPa}$ followed by high frequency oscillations. As with previous tests only a small increase of temperature $\left(\mathrm{T}_{2}\right)$ was recorded.

Finally, several tests were carried out using heavy duty sacs of the kind used in some storage operations in the UK nuclear industry. These sacs, of similar volume to the lighter zip-tie sacs ( $0.02 \mathrm{~mm}$ thick), comprised two $0.3 \mathrm{~mm}$ thick sheets of PVC seam welded on all sides. Figure 11 shows a sequence of still images from the video of a typical test using these sacs. It can be seen that the much thicker sac has made a significant difference to the nature of the explosion. Following ignition there is an extended time period during which a jet flame burns which then after $33 \mathrm{~ms}$ extends far enough to heat thermocouple $\mathrm{T}_{1}$. This longer duration, compared to the thinner bags, possibly relates to a slightly higher initial internal pressure. After $209 \mathrm{~ms}$ the flame can be seen to blow back into the sac and it was apparent that the ejected combustion products/flame was confined to a narrower jet than hitherto and appeared more violent. After the explosion, the area of the hole was only around $1.2 \times 10^{-3} \mathrm{~m}^{2}$ whereas with the thinner zip-tie sacs the hole was around 6 to $11 \times 10^{-3} \mathrm{~m}^{2}$. This is consistent with a considerably higher pressure being developed within the PVC sac. 


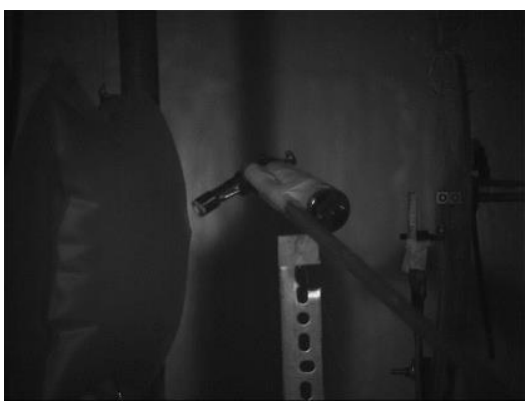

$0 \mathrm{~ms}$

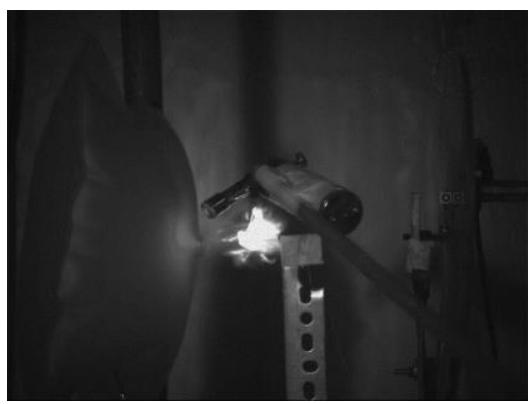

$209 \mathrm{~ms}$

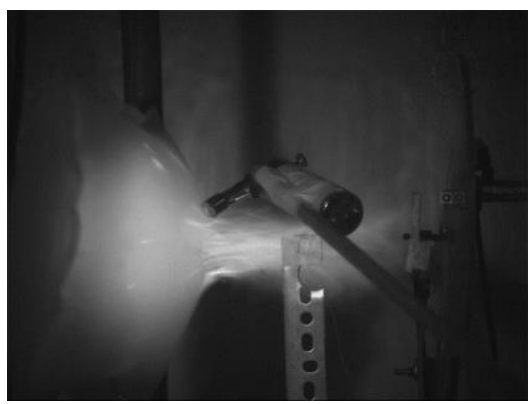

$216 \mathrm{~ms}$

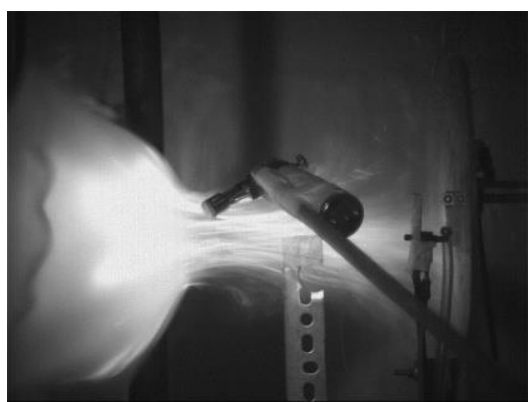

$220 \mathrm{~ms}$

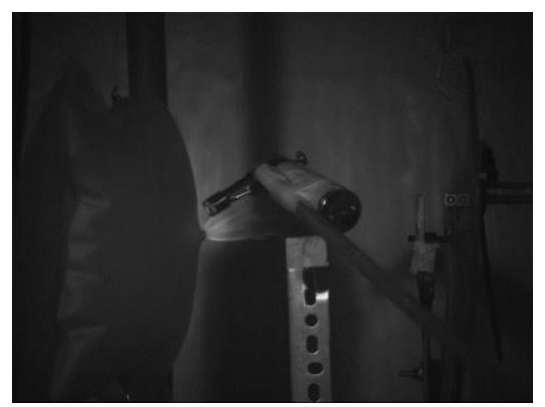

$33 \mathrm{~ms}$

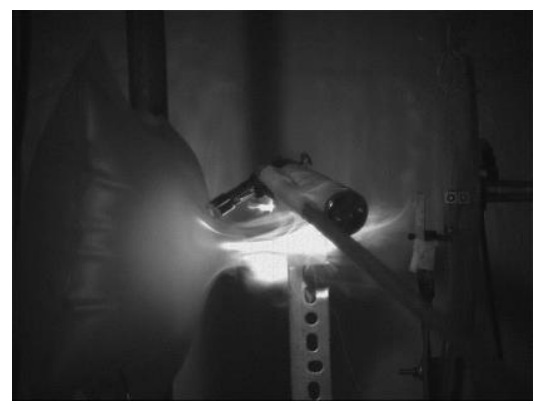

$212 \mathrm{~ms}$

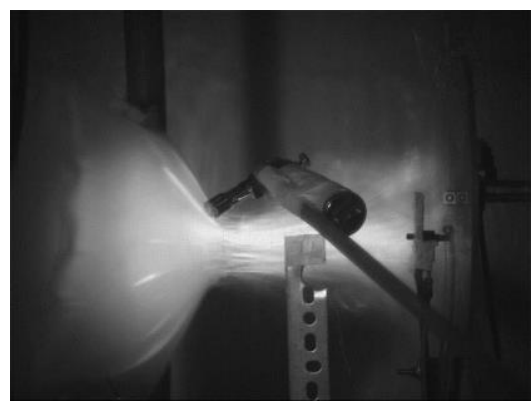

$217 \mathrm{~ms}$

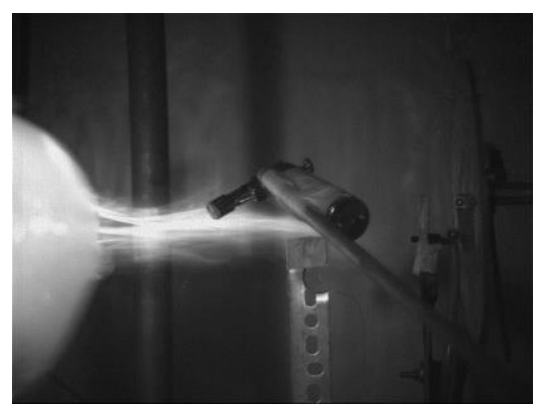

$226 \mathrm{~ms}$

Figure 11. Image frames from ignition of stoichiometric $\mathrm{H}_{2} /$ air mixture in a thick PVC sac with the $0.8 \mathrm{~kg}$ pendulum. 
From the movement of the markers on the pendulum, shown in Figure 12, it was found that the pendulum was accelerated rapidly away from the blast to a velocity exceeding 1 $\mathrm{m} / \mathrm{s}$, considerably greater than that observed with the zip-tie sacs. It was also evident from the tracking measurements, that the initial acceleration to give this stable velocity occurred over a time period of around 6-7 ms which indicated an average initial acceleration of the pendulum in the region of $22 \mathrm{~g}$. This observation is consistent with the typical acceleration force - time history for these tests, shown in Figure 13, where there is an initial period of uni-directional acceleration force. Rapid fluctuation of pendulum movement is smoothed out due to the inertial tendency to resist sudden changes in its current momentum. The accelerometer records the effect of acceleration force on the device rather than physical movement of the pendulum.

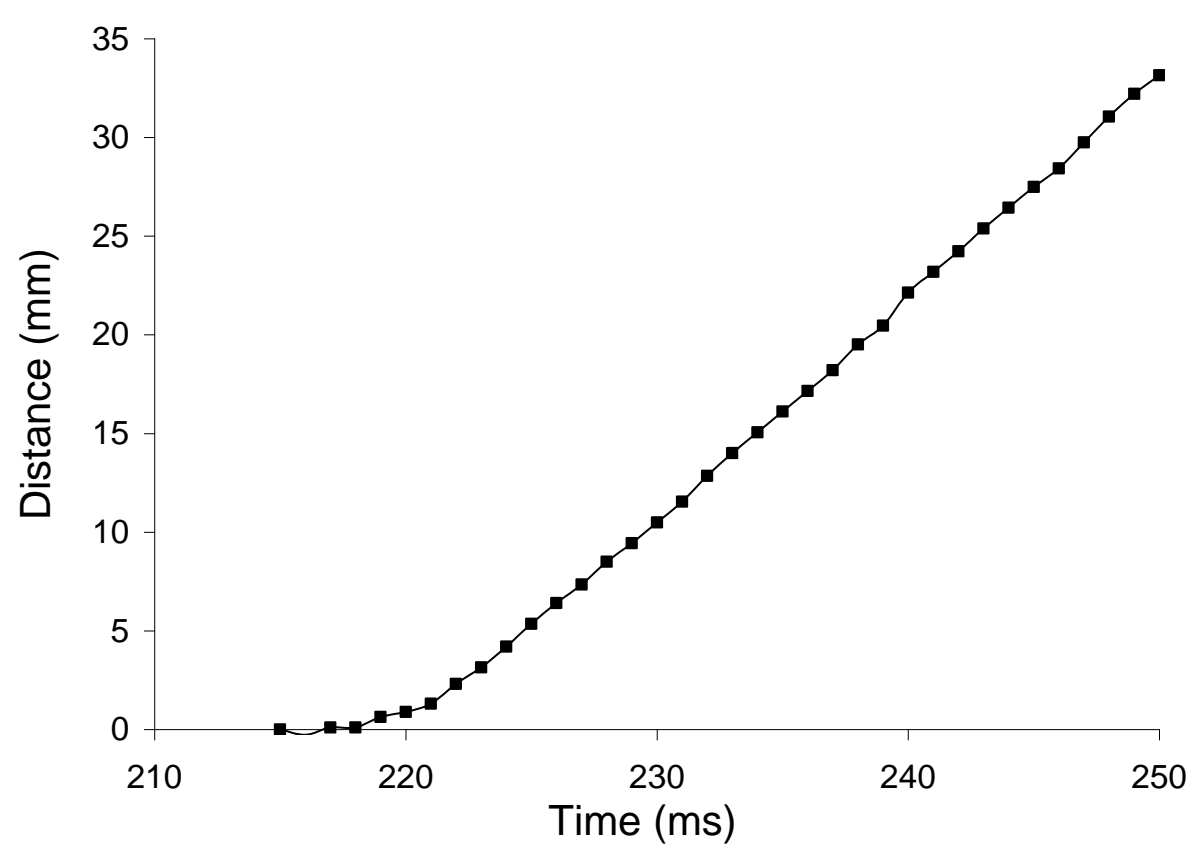

Figure 12. Movement of the $0.8 \mathrm{~kg}$ pendulum resulting from ignition of stoichiometric $\mathrm{H}_{2}$ /air mixture in a thick PVC sac. 


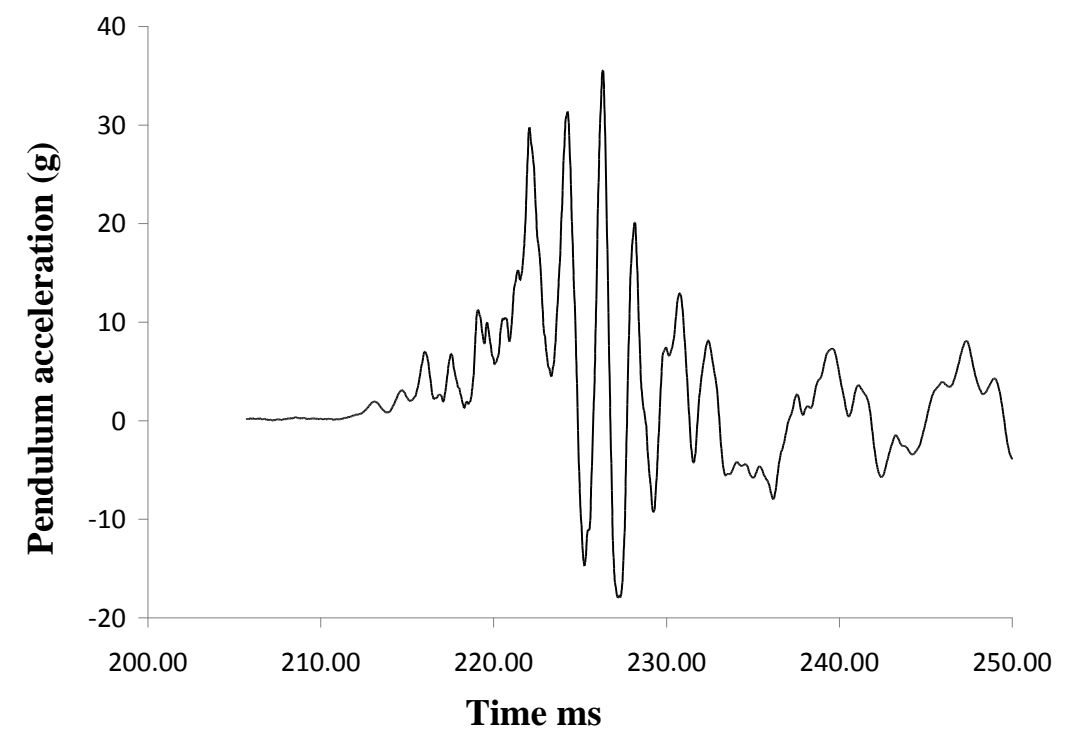

Figure 13. Acceleration force - time history for the $0.8 \mathrm{~kg}$ pendulum after ignition of stoichiometric $\mathrm{H}_{2} /$ air mixture in a thick PVC sac.

Figure 14 shows the output from the pressure sensor located close to the initial position of the pendulum. Comparison with Figure 13 suggests that the initial acceleration of the pendulum coincides with the arrival of the initial impulsive pressure peaks. Following the initial peak of around 1to $1.5 \mathrm{kPa}$ the pressure trace becomes complex with high frequency oscillations, followed by several large spikes the largest of which peaks at nearly $12 \mathrm{kPa}$.

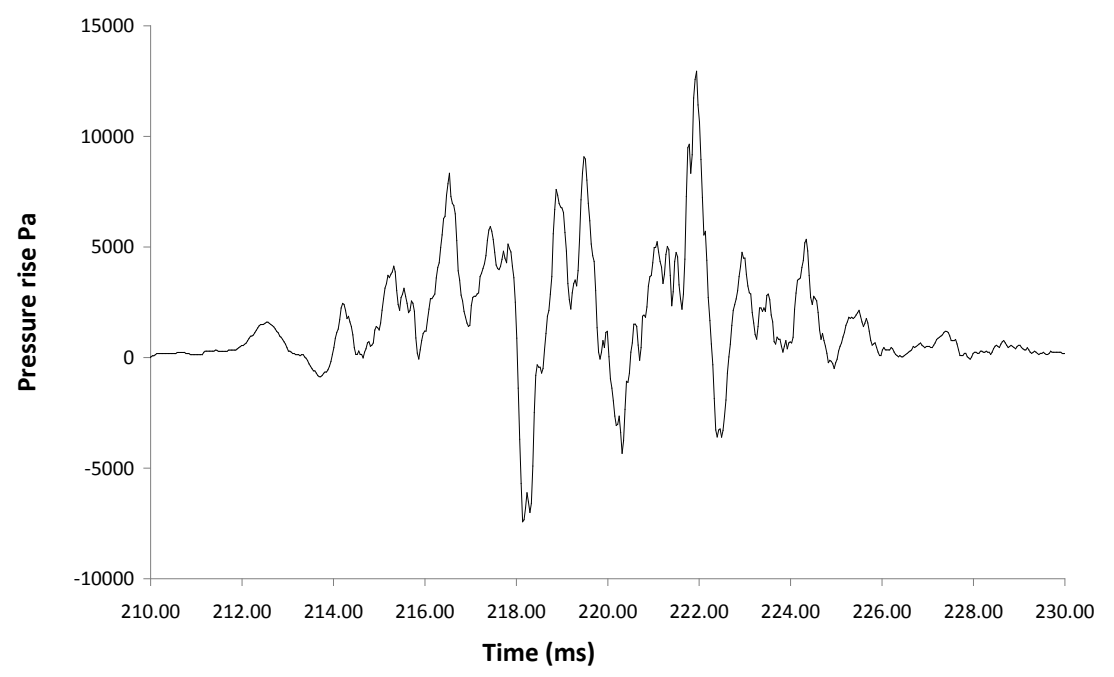

Figure 14. Time history for pressure (position B) developed near the pendulum $(0.8 \mathrm{~kg})$ after ignition of stoichiometric $\mathrm{H}_{2} /$ air mixture in a thick PVC sac. 
Figure 15 shows the temperature recorded during a test on the underside of the $0.037 \mathrm{~mm}$ thick glove material. There is an initial rise of around $4^{\circ} \mathrm{C}$ followed by a slight decay before slowly starting to rise again ending at a rise of around $3^{\circ} \mathrm{C}$ after 1.5 seconds.

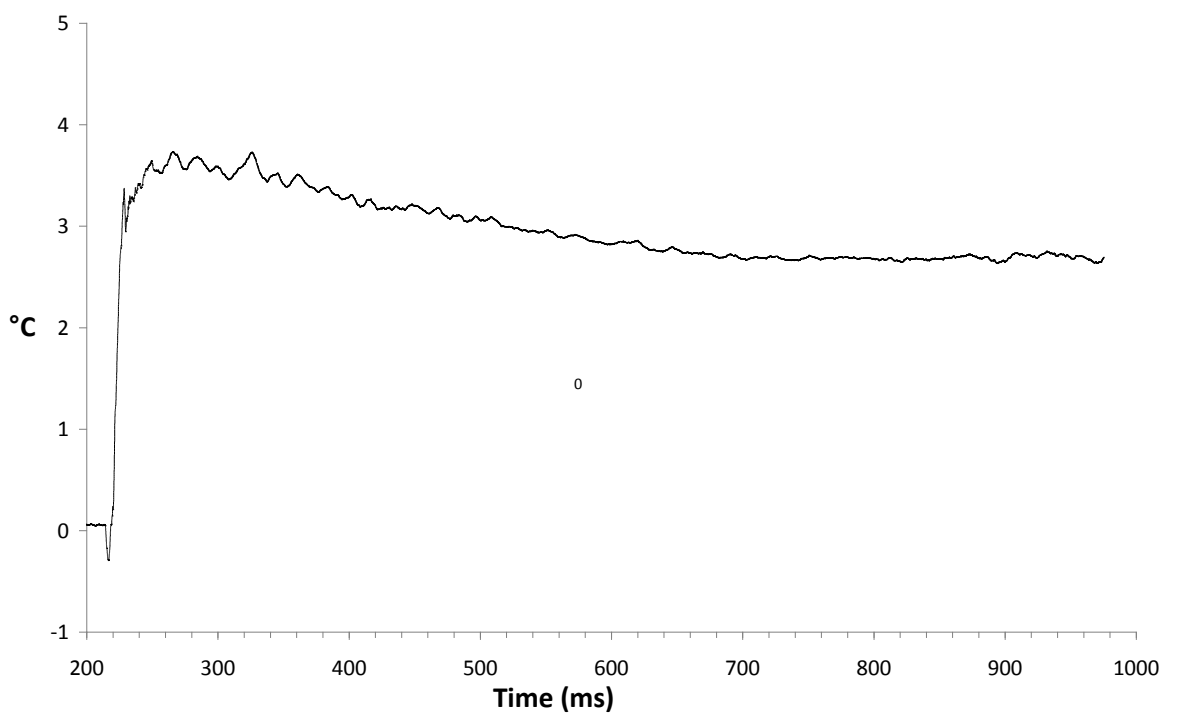

Figure 15. Polymer film temperature rise $\left(\mathrm{T}_{2}\right)$ after ignition of stoichiometric $\mathrm{H}_{2} /$ air mixture in a thick PVC sac.

\section{Noise exposure tests}

The results of the acoustics measurements and corresponding predictive calculations of peak sound pressure levels at $0.6 \mathrm{~m}$ (arm's length) distance from the exploding balloon/sac are given in Table 1. Due to the prevalence of a diffuse sound field in the laboratory the sound levels predicted at arm's length distance are $3.4 \mathrm{~dB}$ higher than those measured at $4.2 \mathrm{~m}$ distance. Two explosion tests were carried out in each case for the balloons, zip-tie sacs and thick PVC sacs. The LCpeak dB values given in the Table are referenced to $20 \mu \mathrm{Pa}$ and exposure limit or action values of the EU Directive (noise) are indicated when the corresponding LCpeak value is predicted to be reached. The lower exposure action value applies when a LCpeak value of $135 \mathrm{~dB}$ is reached and requires the employer to inform, instruct and train employees on the potential risks to health and safety due to the noise exposure. The exposure limit value recorded for one of the PVC sacs indicates a peak sound pressure level which is not permissible.

Table 1. Peak sound pressure level (LCpeak, dB) and European Directive (noise) exposure limit and exposure action values.

\begin{tabular}{|l|c|c|l|}
\hline & Measured at $4.2 \mathrm{~m}$ & Calculated at $0.6 \mathrm{~m}$ & $\begin{array}{l}\text { European Directive exposure } \\
\text { limit and Action values }\end{array}$ \\
Balloon & 123.6 & 127.0 & \\
Balloon & 131.7 & 135.1 & Lower exposure action value \\
Zip-tie sac & 126.8 & 130.2 & \\
Zip-tie sac & 126.6 & 130.0 & \\
\hline
\end{tabular}




\begin{tabular}{|l|c|c|l|}
\hline PVC sac & 132.2 & 135.6 & Lower exposure action value \\
PVC sac & 140.1 & 143.5 & Exposure limit value \\
\hline
\end{tabular}

\section{Discussion}

For the reasons given earlier, tests were conducted to investigate three main possible types of injury, namely; physical injury from the force of the blast, burn damage and hearing damage resulting from the blast/shock wave. Considering first the shock loads imparted by the blast from the weakly confined, small volume deflagrations, it seems very unlikely that the loads generated would be sufficient to cause significant physical injury. With the heavier pendulum, similar in mass to a human head, no response was recorded by the accelerometer in any of the tests and no visual movement of the pendulum was observed from the digital imaging. Tests with the much lighter pendulum show movement in the digital imaging together with corresponding accelerometer readings. The stable net directional velocity of $0.16 \mathrm{~m} / \mathrm{s}$ observed from the digital imaging over a period of a few milliseconds indicated that the pendulum movement with the zip-tie sac was associated with a blast force that resulted in a net unidirectional acceleration of around $5 \mathrm{~g}$. Given the short duration of this acceleration period and that a human head with 6 times the mass of the lighter pendulum would be subject to less acceleration force given a similar applied loading, it can be seen from Fig.1 that the blast is very much below that considered likely to cause serious injury/concussion.

The tests carried out using the much thicker and stronger Sellafield supplied sacs, however, produced significantly greater shock loads. The accelerometer in one of these tests registered a maximum for a very short period that exceeded $30 \mathrm{~g}$ (Figure 13) and the pendulum was accelerated to just over $1 \mathrm{~m} / \mathrm{s}$ (i.e. around 5-6 times greater than with the zip-tie sac tests). Again, had the heavier pendulum been used, the initial averaged unidirectional acceleration would have clearly been much less than that indicated $(22 \mathrm{~g})$ and so considerably less than would be required to cause personal injury. It should be noted however, that the thicker sacs can clearly withstand a significant overpressure (as evidenced by the smaller area bursting/vent hole), so that should an ignition occur inside the sac prior to puncture, the blast on bursting could be much greater. The proximate head pendulum used in the study is also only representational and not biofidelic in respect to shape and internal head features.

Regarding the possibility of burn damage, this seems very unlikely from the results of this study. Although flames/hot gases clearly impinged on the polymer film, it was for a very short time and there were no signs of damage/burning of the film sample used in any of the tests. Part of the film sample had been deliberately allowed to overhang the mounting putty to leave a free edge vulnerable to ignition. The flame temperatures would likely (noting the thermocouple time constant) have peaked well in excess of that required to start to melt/ignite the material (ca $200-500^{\circ} \mathrm{C}$ ) but for only a very short time period. The heat flux to the polymer surface during this time would be as a result of both convection and radiation and will vary over the course of the explosion. The temperatures recorded on the underside of the polymer glove film showed a maximum temperature rise in the polyethylene zip-tie sac tests of only $2.4^{\circ} \mathrm{C}$. In the case of the 
thicker Sellafield PVC sac tests the maximum temperature rise was $4^{\circ} \mathrm{C}$. This is clearly insufficient to cause burn damage to flesh in contact with the glove material.

The acoustic measurements and noise exposure assessment carried out in this study clearly suggest that hearing damage could result from the ignition of small volumes of hydrogen/air gas mixture. Although the sound levels recorded in the case of the thin ziptie sacs were lower than that which would be required to trigger action under European regulations, this was not the case with the thick PVC sacs. Assessing the predicted levels at arm's length against the relevant European Directive (noise), the two instances of gas ignition in the PVC sacs reached action values whilst one of the rubber balloon explosions reached the lower exposure action limit. Given that the predicted sound levels would significantly increase at shorter than full arm's length distance, with larger sacs or with increase in oxygen concentration, the possibility of hearing damage should be considered the most likely threat to the health of operatives subjected to the ignition of small volumes of weakly contained hydrogen/air gas mixture.

Finally, it must be emphasized that the findings in this study relate to the ignition of weakly confined flammable gas mixture and that the consequences of strongly confined gas explosions could be considerably more injurious. Taking into account, the work of Vernon and Gee [20] it is also apparent that the consequences arising from ignition with increased oxygen content in the sacs are likely to be more serious than reported in this article. It should be further noted that the injurious effect of any shrapnel has not been considered.

\section{Conclusions}

A study has been conducted to investigate the potential for injury from ignition of small weakly confined volumes ( 3-4 litres) of hydrogen/air $(\Omega=1)$ in close proximity to an operator. Given the nature of the personal protective equipment that would be expected to be employed by such operators as a matter of course (i.e. of significantly thicker material than the film employed in these tests) it is concluded that the risk of injury from burns is likely to be very small. Similarly, the measurements obtained regarding blast pressures and acceleration forces suggest that even for the worst case scenario investigated (i.e. with thick PVC sacs) there is unlikely to be any direct physical injury. The situation that would arise with strongly contained gas mixtures, with ignition initiated within the package or with the possibility of shrapnel fragments has not been investigated in this study but would be expected to lead to quite different findings. It has been shown, however, that even with weakly confined explosions, the possibility that hearing damage would occur is a matter of concern that should focus future attention and effort.

\section{Acknowledgments}

The Hydrogen Hazards Unit and Dr. Luis Gomez-Agustina at London South Bank University would like to acknowledge the financial support of Sellafield Ltd. and the University in undertaking this programme of work. 


\section{References}

1. Zhang Q, Li D. Comparison of the explosion characteristics of hydrogen, propane, and methane clouds at the stoichiometric concentrations. International Journal of Hydrogen Energy 2017; 42:14794-14808.

2. Dadashzadeh 1M, Kashkarov S, Makarov D, Molkov V. Risk assessment methodology for onboard hydrogen storage. International Journal of Hydrogen Energy 2018; 43:64626475.

3. Rigas F and Sklavounos S. Evaluation of hazards associated with hydrogen storage facilities. International Journal of Hydrogen Energy 2005; 30:1501-1510.

4. Ekoto IW, Houf WG, Evans GH, Merilo EG, Groethe MA. Experimental investigation of hydrogen release and ignition from fuel cell powered forklifts in enclosed spaces. International Journal of Hydrogen Energy 2012; 37:17446-17456.

5. Tanaka T, Azuma T, Evans JA, Cronin PM, Johnson DM,Cleaver RP. Experimental study on hydrogen explosions in a full-scale hydrogen filling station model. International Journal of Hydrogen Energy 2007; 32:2162-2170.

6. Mevel R, Sabard J, Lei J, Chaumeix N. Fundamental combustion properties of oxygen enriched hydrogen/air mixtures relevant to safety analysis: Experimental and simulation study. International Journal of Hydrogen Energy 2016; 41:6905-6916.

7. Petukhov VA, Naboko IM, Fortov VE. Explosion hazard of hydrogen/air mixtures in the large volumes. International Journal of Hydrogen Energy 2009; 34:5924-5931.

8. Saffers JB, Molkov VV. Hydrogen safety engineering framework and elementary design safety tools. International Journal of Hydrogen Energy 2014; 39:6268-6285.

9. Tretsiakova-McNally S. LECTURE - Dealing with hydrogen explosions. EU report, HyResponse, Grant agreement 325348.

www.hyresponse.eu/files/Lectures/Dealing_with_hydrogen_explosions_notes.pdf.

Accessed 2nd Oct. 2018.

10. Tretsiakova-McNally S. LECTURE - Safety of hydrogen storage. EU report, HyResponse, Grant agreement 325348.

www.hyresponse.eu/files/Lectures/Safety_of_hydrogen_storage_notes.pdf. Accessed 2nd Oct. 2018.

10. Tretsiakova-McNally S. LECTURE - Hydrogen properties relevant to safety. EU report, HyResponse, Grant agreement 325348. 
www.hyresponse.eu/files/Lectures/Hydrogen_properties_relevant_to_safety_notes.pdf. Accessed 2nd Oct. 2018

11. Jones SJ, Averill AF, Ingram JM, Holborn PG, Battersby P, Nolan PF, et al. Impact ignition of hydrogen - air mixtures, In: Hazards XIX. Process Safety and Environmental Protection. Symposium Series No 151; IChemE; 2006. pp 401-409.

12. Averill AF, Ingram JM, Holborn PG, Battersby P, Nolan PF. Ignition of flammable hydrogen/air mixtures by controlled glancing impacts in nuclear decommissioning. Paper No 234, $5^{\text {th }}$ Int.Conf. on Hydrogen Safety, Sept. 9 - 11, 2013, Brussels, Belgium.

13. Averill AF, Ingram JM, Battersby P, Holborn PG. Ignition of flammable hydrogen in air (and other $\mathrm{H}_{2} / \mathrm{N}_{2} / \mathrm{O}_{2}$ mixtures) by mechanical stimuli. Part 3: Ignition under conditions of low sliding velocity $(<0.8 \mathrm{~m} / \mathrm{s})$. International Journal of Hydrogen Energy 2015;40:9847-9853.

14. Averill AF, Ingram JM, Holborn PG, Battersby P, Benson CM. Application of Bayesian methods and networks to ignition hazard event prediction in nuclear waste decommissioning operations. Process Safety and Environmental Protection 2018; 116:396-404.

15. Glover NJ. The effects of explosions on the body. http://www.fireengineering.com/articles/print/volume-155/issue-3/features/the-effects-ofexplosions-on-the-body.html (accessed Sept 2017)

16. Bass C, Davis M, Rafaels K, Rountree M, Harris RM, Sanderson E et al. A methodology for assessing blast protection in explosive ordinance disposal bomb suits. Int. J. Occupational Safety and Ergonomics (JOSE) 2005;11(4):347-361

17. Versace J. A review of the severity index. Proc. 15th Stapp Car Crash Conf. Soc. of Automotive Engineers. NY 1971. PP 771-796.

18. Greenwald RM, Gwin JT, Chu JJ and Crisco JJ. Head impact severity measures for evaluating mild traumatic brain injury risk exposure. Neurosurgery 2008;62(4):789-798.

19. Hurley, Morgan J., Gottuk, Daniel T., Hall Jr., John R.,"SFPE Handbook of Fire Protection Engineering”, 5th ed. New York: Springer. 2016. p2713.

20. Vernon JA, Gee KL. Acoustical characterisation of exploding hydrogen-oxygen balloons. J. Acoust. Soc. Am. 2012; 131(3). Doi.org/10.1121/1.3684741.

21. The Control of Noise at Work Regulations 2005. SI 2005/1643, London: HMSO.

22. British Standards Institution (2001) BS EN 60804: 2001: Integrating-averaging sound level meters. 
23. British Standards Institution (2008) BS ISO 3382-2: 2008 Acoustics. Measurement of room acoustic parameters. Reverberation time in ordinary rooms.

24. Z-51,Comparison of time constant vs. overall outside diameter of bare thermocouple wires or grounded junction thermocouples in air. Omega. Stamford, CT 06907, USA. Accessed on $1^{\text {st }}$ March 2018 from http://www.omega.com/techref/pdf/z 